\title{
Charge Carrier Dynamics in Materials with Disordered Structures: A Case Study of Iron Phosphate Glasses
}

\author{
Ana Šantić* and Andrea Moguš-Milanković \\ NMR Center, Ruđer Bošković Institute, 10000 Zagreb, Croatia
}

RECEIVED OCTOBER 9, 2011; REVISED APRIL 12, 2012; ACCEPTED APRIL 24, 2012

\begin{abstract}
Materials with disordered structures have a crucial role in the rapid development of new technologies. Improvement of these materials for particular application, as well as preparation of novel composites is based on a thorough understanding of the basic mechanisms of charge carrier transport. Among various classes of structurally disordered materials, a family of iron phosphate glasses attracts special attention due to their unique combination of structural, electrical and mechanical properties. Generally, iron phosphate glasses are electronically conducting glasses with polaronic conduction mechanism where conduction takes place by electrons hopping from $\mathrm{Fe}^{2+}$ to $\mathrm{Fe}^{3+}$. Consequently, polaron transport directly depends on $\mathrm{Fe}^{2+} / \mathrm{Fe}_{\text {tot }}$ ratio and overall $\mathrm{Fe}_{2} \mathrm{O}_{3}$ content. However, by altering composition (addition of $\mathrm{Cr}_{2} \mathrm{O}_{3}$, $\mathrm{MoO}_{3}, \mathrm{PbO}, \mathrm{Na}_{2} \mathrm{O}$ ) and preparation conditions, the electrical conductivity of iron phosphate based glasses may vary over many orders of magnitude. This paper gives an overview of our recent studies of electronic and ionic transport in iron phosphate based glasses. (doi: 10.5562/cca1989)
\end{abstract}

Keywords: iron phosphate glasses, electrical properties, structure

\section{INTRODUCTION}

Over the last several decades materials with disordered structure such as glasses, polymers, molten salts and gels have been investigated intensively. Specific electrical properties of these materials make them attractive for application in various electrochemical devices, from the Li-batteries, supercapacitors, fuel cells, electrochromic windows to the photovoltaic cells. Among different types of structurally disordered materials, oxide glasses have a special place due to their relatively simple production procedure, easy molding into desired shapes and a wide range of possible compositions which results in a large variability in glass properties.

From the scientific, as well as technological point of view, the basic questions of interest are: How good oxide glasses can conduct the electricity and what are the mechanisms of charge carrier transport in these materials? On the electrical conductivity chart of materials, "common" oxide glasses are usually placed in the insulator category with the typical room temperature values from $10^{-12}$ to $10^{-16}(\Omega \mathrm{cm})^{-1}$. ${ }^{1}$ However, numerous investigations of variety of oxide glass systems have shown that by changing the composition it is possible to cover many orders of magnitude in the conductivity. In particular, the addition of $\mathrm{V}_{2} \mathrm{O}_{5}$ or $\mathrm{AgI}$ to some silicate and phosphate glasses can increase this value even up to $10^{-3}(\Omega \mathrm{cm})^{-1} \cdot{ }^{2,3}$ The ability of glass to conduct electricity, therefore, depends strongly on the composition. Naturally, the glass composition determines the type of charge carriers. Oxide glasses containing monovalent cations $\left(\mathrm{Na}^{+}, \mathrm{Li}^{+}, \mathrm{Ag}^{+}\right)$exhibit ionic conductivity, whereas, glasses containing transition metal oxides $\left(\mathrm{V}_{2} \mathrm{O}_{5}, \mathrm{Fe}_{2} \mathrm{O}_{3}, \mathrm{WO}_{3}, \mathrm{MoO}_{3}\right)$ show electronic conductivity. If the glass contains both, monovalent cations and transition metal oxide, a mixed ionic-electronic transport takes place.

Iron phosphate glasses belong to an important group of oxide glasses because of their low melting and softening temperature, excellent chemical durability, high thermal expansion coefficient and wide glass forming region. ${ }^{4-8}$ The first report on electrical transport in binary iron phosphate glasses was published by Hansen ${ }^{9}$ in 1965 and since then, the interest in this glass system has been growing rapidly. It is well established that $\mathrm{Fe}_{2} \mathrm{O}_{3}-\mathrm{P}_{2} \mathrm{O}_{5}$ glasses exhibit electronic conduction with a polaronic conduction mechanism. ${ }^{8,10-14}$ The electronic conductivity behavior is a result of the iron ions being in two valence states where conduction takes place by thermally activated small polaron hopping from $\mathrm{Fe}^{2+}$ to $\mathrm{Fe}^{3+}$ sites. Consequently, polaron transport directly depends on $\mathrm{Fe}^{2+} / \mathrm{Fe}_{\text {tot }}$ ratio and overall $\mathrm{Fe}_{2} \mathrm{O}_{3}$ content.

\footnotetext{
* Author to whom correspondence should be addressed. (E-mail: asantic@irb.hr)
} 
The electrical properties of iron phosphate glasses prepared by conventional melt quenching have been investigated in our research group for more than a decade. We have been studying the influence of addition of other oxides (alkali, earth alkali and transition metal oxides) on the polaronic conduction and structure of iron phosphate glass. This paper gives an overview of our findings and addresses some important issues of the electrical characterization of glasses in general. As a starting point, the fundamentals of impedance spectroscopy, as a main method used for studying electrical properties are given in order to illustrate the possibilities of this powerful technique.

\section{IMPEDANCE SPECTROSCOPY}

Impedance spectroscopy (IS) is a powerful method for characterizing the electrical properties of materials and their interfaces. The basic principle is to apply a small amplitude alternating voltage $\widehat{U}$ (Eq. 1) to the sample placed between two electrodes and to measure the current response $\widehat{I}$ (Eq. 2):

$$
\begin{aligned}
& \widehat{U}=U_{0} \cdot \exp (i \omega t) \\
& \widehat{I}=I_{0} \cdot \exp i(\omega t+\varphi)
\end{aligned}
$$

where $I_{0}$ and $U_{0}$ are the amplitudes of current and voltage, respectively, $\omega$ is the angular frequency and $\varphi$ is the phase difference between current and voltage. The amplitude of the resulting current and its phase depend on the electrical properties of the sample. The ratio of the applied voltage and resulting current gives the complex impedance of the sample:

$$
\begin{aligned}
& \hat{Z}=\frac{\widehat{U}}{\widehat{I}}=\frac{U_{0}}{I_{0}} \cdot \exp (-i \varphi)=|\hat{Z}| \cdot \exp (-i \varphi)= \\
& |\hat{Z}| \cos \varphi-i|\hat{Z}| \sin \varphi=Z^{\prime}-i Z^{\prime \prime}
\end{aligned}
$$

In general, the complex impedance, $\hat{Z}$, is frequency-dependent, so the conventional impedance spectroscopy consists of the measurement of $\bar{Z}$ as a function of frequency over a wide range (the high-frequency limit is typically few $\mathrm{MHz}$ ). Finally, the information about the electrical properties of the material can be derived from the resulting structure of $\bar{Z}$ vs. $v$ or $\omega$ response.

There are three complex functions which are related to the complex impedance:

$$
\text { the complex admittance: } \quad \hat{Y}=\frac{1}{\hat{Z}}=Y^{\prime}+i Y^{\prime \prime}
$$

the complex permittivity: $\quad \hat{\varepsilon}=\frac{\hat{Y}}{i \omega C_{o}}=\varepsilon^{\prime}-i \varepsilon^{\prime \prime}$

the complex modulus: $\quad \hat{M}=\frac{1}{\hat{\varepsilon}}=M^{\prime}+i M^{\prime \prime}$

where $C_{0}=\varepsilon_{0} A / d$ is the vacuum capacitance of the cell with electrode area, $A$, and sample thickness, $d$.

From the measured impedance, the complex conductivity, $\hat{\sigma}$, can be calculated according to the equation:

$$
\hat{\sigma}=\frac{1}{\hat{Z}} \cdot \frac{d}{A}=\sigma^{\prime}+i \sigma^{\prime \prime}
$$

The complex functions 3-7 show different dependence on frequency and they are all valuable for electrical characterization of materials. Various polarization and charge transfer processes which occur in the electrode-material system (over the measured frequency range) are highlighted by different formalisms. Its versatility makes this technique powerful in the studying electrical properties of electrode-material systems.

\section{Analysis of the Impedance Spectroscopy Results}

There are basically two approaches in analyzing the results of impedance spectroscopy. The first one is to present the data in a spectroscopic plot (the real and imaginary components as a function of $\log (v))$ and to analyze the specific features of their frequency dependence which contain information on the relaxation processes and charge carrier dynamics at different time scales. The second approach is to analyze the complex impedance plane (imaginary, $Z^{\prime \prime}$, against the real, $Z^{\prime}$, impedance), by means of equivalent circuit modelling. In the simple case, sample shows a semicircle with the center at the real axis, Figure 1. The low frequencies

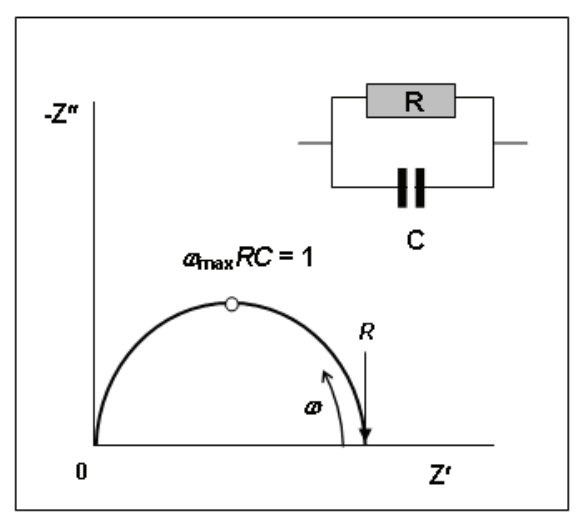

Figure 1. Schematic figure shows the complex impedance plane and corresponding equivalent circuit model. 
intercept corresponds to the resistance of the sample, while, capacitance is separable through the relation $\omega_{\max } R C=1$, which holds at the frequency of the $Z^{\prime \prime}$ maximum. Such impedance response can be well approximated by the equivalent circuit model build up of resistor and capacitor in parallel. Generally, the complex impedance plots contain different features (dual semicircular arcs, low-frequency spurs etc.) depending on the polarization processes in the sample-electrode system. Each impedance spectrum can be modelled by appropriate equivalent circuit that contains electrical elements (resistors, capacitors, inductors) that represent physical properties of the sample-electrode system. Therefore, the polarization processes with different relaxation times (electrode effects, conduction in a grain core and conduction in a grain boundary) can be easily separated. $^{15,16}$

In this paper we present both approaches in the electrical characterization of iron phosphate glasses.

\section{BINARY IRON PHOSPHATE GLASSES}

\section{Structure}

Binary iron phosphate glasses exist in a wide compositional range; up to approximately $50 \mathrm{~mol} \% \mathrm{Fe}_{2} \mathrm{O}_{3}$ can be easily vitrified in phosphate melt. With increasing $\mathrm{Fe}_{2} \mathrm{O}_{3}$ content phosphate network goes through the systematic depolymerization which can be easily detected by Raman spectroscopy, Figure 2. The structural units in phosphate network are usually classified according to the $\mathrm{Q}^{n}$ notation, where $n(n=0-3)$ represents the number of bridging oxygen atoms per $\mathrm{PO}_{4}$ tetrahedron. The Raman bands in the $1000-1300 \mathrm{~cm}^{-1}$ range are due to the symmetric and asymmetric stretching modes of P-non-bridging oxygen bonds, whereas bands in the $680-720 \mathrm{~cm}^{-1}$ range are due to the symmetric and asymmetric stretching modes of bridging oxygen atoms. ${ }^{17,18}$ With increasing $\mathrm{Fe}_{2} \mathrm{O}_{3}$ content the frequency of the most prominent stretching mode of non-bridging oxygen decreases consistently, from $1200 \mathrm{~cm}^{-1}$ (symmetric $\mathrm{PO}_{2}$ stretch in $\mathrm{Q}^{2}$ tetrahedra) to $1071 \mathrm{~cm}^{-1}$ (symmetric $\mathrm{PO}_{3}$ stretch in $\mathrm{Q}^{1}$ tetrahedra) and finally to $1003 \mathrm{~cm}^{-1}$ (symmetric $\mathrm{PO}_{4}$ stretch in $\mathrm{Q}^{0}$ tetrahedra) indicating progressive depolymerization of the phosphate network. Glasses with small amount of $\mathrm{Fe}_{2} \mathrm{O}_{3}$ show metaphosphate chain-like structure $\left(Q^{2}\right)$, with further addition of $\mathrm{Fe}_{2} \mathrm{O}_{3}$ the structure becomes pyrophosphate with basic $\mathrm{Q}^{1}$ dimers, and finally orthophosphate structure with isolated $\mathrm{Q}^{0}$ units. Such changes in phosphate network have direct influence on the properties of glass. Phosphate glasses poor in $\mathrm{Fe}_{2} \mathrm{O}_{3}$ are hygroscopic. The addition of $\mathrm{Fe}_{2} \mathrm{O}_{3}$ drastically increases the chemical durability due to the replacement of the bridging $\mathrm{P}-\mathrm{O}-\mathrm{P}$ bonds by more moisture resistant $\mathrm{P}-\mathrm{O}-\mathrm{Fe}$

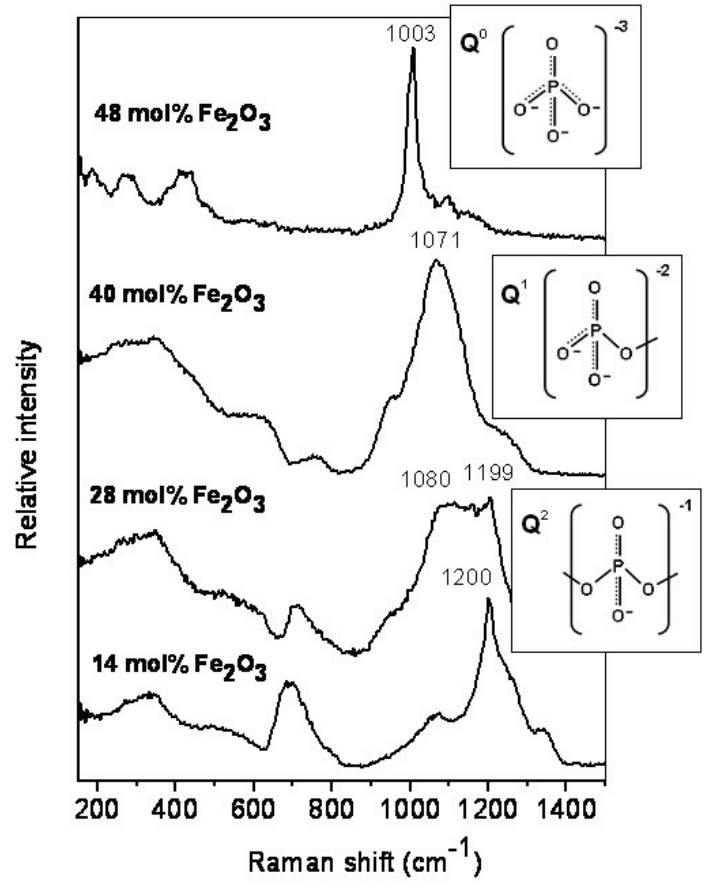

Figure 2. Raman spectra of $x \mathrm{Fe}_{2} \mathrm{O}_{3}-(100-x) \mathrm{P}_{2} \mathrm{O}_{5}, 14 \leq x \leq$ 48, (mol \%) glasses.

bonds. ${ }^{5-7}$ Simultaneously, with the increase of $\mathrm{Fe}_{2} \mathrm{O}_{3}$ content, the crystallization tendency of the glass increases. The competition of these unwanted properties, defines the optimal glass composition, namely $40 \mathrm{Fe}_{2} \mathrm{O}_{3}-$ $60 \mathrm{P}_{2} \mathrm{O}_{5}(\mathrm{~mol} \%)$, which exhibits excellent chemical durability and low crystallization tendency. This glass composition is widely studied and often selected as a parent glass for complex multicomponent glass systems.

\section{Electronic Conduction}

The basic condition for electronic transport in binary iron phosphate glasses is the existence of iron ions in different valence states, as $\mathrm{Fe}^{2+}$ and $\mathrm{Fe}^{3+}$. This is indeed satisfied even if the starting batch contains only $\mathrm{Fe}^{2+}$ as $\mathrm{FeO}$ or $\mathrm{Fe}^{3+}$ as $\mathrm{Fe}_{2} \mathrm{O}_{3}$. The reason for this phenomenon is the reversible redox reaction (1) that occurs during melting and upon cooling the equilibrium concentrations of $\mathrm{Fe}^{2+}$ and $\mathrm{Fe}^{3+}$ ions remain in the glass.

$$
4 \mathrm{Fe}^{3+}(\text { melt })+2 \mathrm{O}^{2-}(\text { melt }) \rightleftarrows 4 \mathrm{Fe}^{2+}(\text { melt })+\mathrm{O}_{2}(\text { gas })(1)
$$

The reaction (1) depends upon several factors such as melting temperature, time, atmosphere, types of raw materials and the presence of other substances in the batch. By varying these factors the fraction of $\mathrm{Fe}^{2+}$ ions in the glass is changing which directly influences the electrical conductivity. For instance, the increase of the melting temperature from 1423 to $1673 \mathrm{~K}$ for $40 \mathrm{Fe}_{2} \mathrm{O}_{3}$ - 

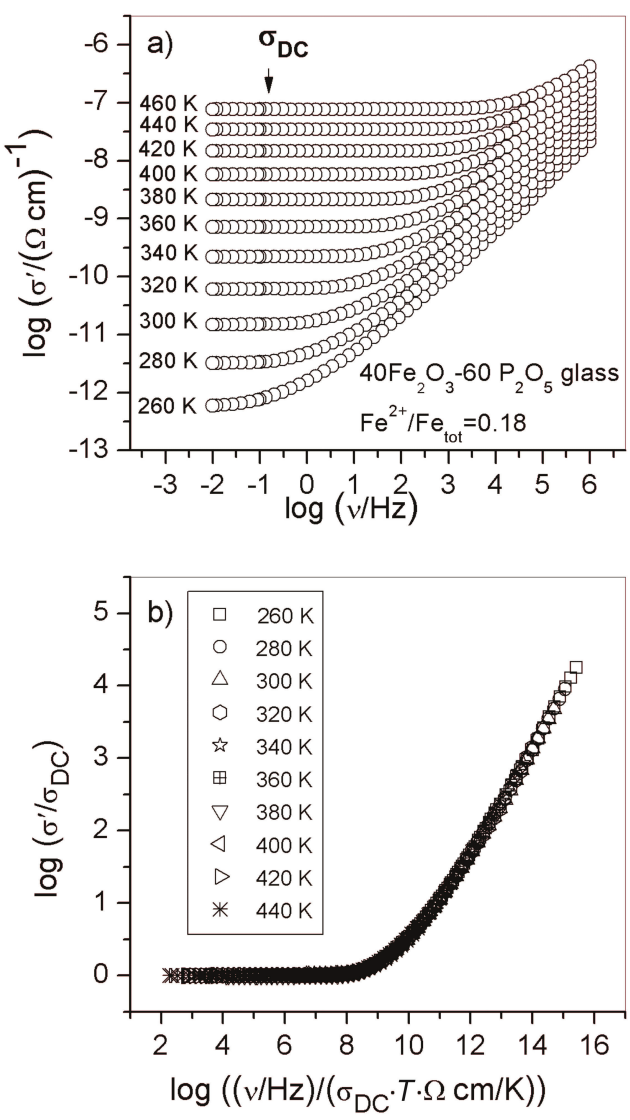

Figure 3. Conductivity spectra (a) and scaled conductivity (b) of $40 \mathrm{Fe}_{2} \mathrm{O}_{3}-60 \mathrm{P}_{2} \mathrm{O}_{5}(\mathrm{~mol} \%)$ glass.

$60 \mathrm{P}_{2} \mathrm{O}_{5}(\mathrm{~mol} \%)$ glass causes the increase of $\mathrm{Fe}^{2+} / \mathrm{Fe}_{\text {tot }}$ ratio from 17 to $50 \%$ which consequently results in the significant increase in electrical conductivity, from 3.6 $\times 10^{-11}$ to $1.0 \times 10^{-9}(\Omega \mathrm{cm})^{-1}{ }^{19}$

It is well known that the mechanism of electronic transport in iron phosphate glasses is explained by the small polaron theory. Generally, small polarons are defined as charge carriers trapped by self-induced lattice distortions which extend over their nearest surroundings. Since the electron drift mobility in these glasses is very low, generally below $10^{-4} \mathrm{~cm}^{2}(\mathrm{~V} \mathrm{~s})^{-1}$ the interaction is strong enough to form small polarons. The transport of these quasi-particles consists of phonon assisted hopping process.

The following sections discuss the frequency and temperature dependence of conductivity and characteristic complex impedance plane of iron phosphate glasses exhibiting polaronic conduction.

\section{Conductivity Spectra}

Typical conductivity spectra of iron phosphate glass at different temperatures are shown in Figure 3a. At each temperature, spectrum consists of two domains. At low frequencies conductivity is frequency independent (so called DC conductivity, $\sigma_{\mathrm{DC}}$ ), whereas, with increasing frequency, conductivity starts to increase in a power-law fashion giving rise to so called dispersion, $\sigma(\omega)$. With increasing temperature, the crossover frequency from the DC to the dispersive regime increases.

The most intriguing fact about the spectral features i.e. conductivity dispersion observed in Figure $3 a$ is that they are common to other glass systems and many other materials independent of the type of charge carriers (polarons and/or ions). ${ }^{20-22}$ It seems that the only common property of all materials that show this power-law behaviour is some kind of structural disorder. This universality for many different classes of materials was first pointed out by Jonscher, who referred to it as a "Universal Dynamic Response" (UDR). ${ }^{23}$ The physical origin of this phenomenon is still not completely resolved, but the dispersion clearly reflects non-random or correlated motions of charge carriers occurring on relatively short time scales. The frequency dependence of conductivity in the IS frequency range $(<10 \mathrm{MHz})$ obeys a Jonscher power law:

$$
\sigma(\omega)=\sigma_{\mathrm{DC}}+A \omega^{s}
$$

where the prefactor $A$ and the frequency exponent $s$ are both weakly temperature-dependent and it is generally found that $s \leq 1$.

At higher frequencies, typically above $100 \mathrm{MHz}$, Jonscher equation fails to describe the frequency dependence since the exponent $s$ must generally increase with frequency in order to fit spectra properly. ${ }^{21}$

A more general approach in analyzing frequency dependent conductivity includes the investigation of influence of temperature on the shape of the conductivity spectra; i.e. scaling properties of material. One of the most popular scaling procedures is the Summerfield scaling ${ }^{24}$ expressed by the relation:

$$
\sigma(\omega) / \sigma_{\mathrm{DC}}=\omega /\left(T \sigma_{\mathrm{DC}}\right)
$$

Figure $3 b$ shows the result of Summerfield scaling of the conductivity isotherms of $40 \mathrm{Fe}_{2} \mathrm{O}_{3}-60 \mathrm{P}_{2} \mathrm{O}_{5}(\mathrm{~mol} \mathrm{\%})$ glass from the Figure 3a. Obviously, conductivity spectra of different temperatures can be scaled to fall on a single master curve indicating time temperature superposition (TTS) ${ }^{21}$ The validity of the TTS principle is observed in many iron phosphate glasses and clearly indicates that the mechanism of polaronic conduction does not change with temperature.

\section{Conductivity}

Above room temperature, conduction in iron phosphate glasses is due to phonon assisted hopping of polarons 


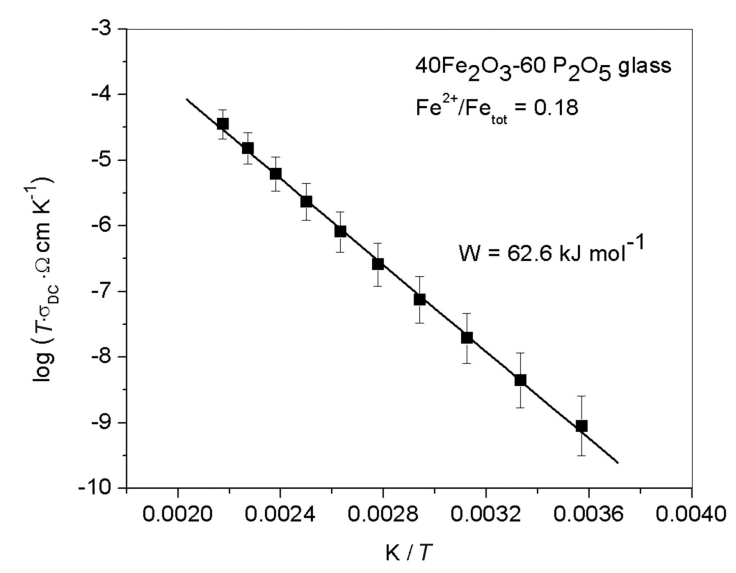

Figure 4. Arrhenius plot of $40 \mathrm{Fe}_{2} \mathrm{O}_{3}-60 \mathrm{P}_{2} \mathrm{O}_{5}$ (mol \%) glass. Solid line represents the least-square linear fits to experimental data.

between nearest neighbouring sites, and the DC conductivity, $\sigma_{\mathrm{DC}}$, shows an Arrhenius temperature dependence, Figure 4. On the basis of a simple diffusion model, Mott ${ }^{11}$ has proposed an equation for DC conductivity in polaronic glasses:

$$
\sigma_{D C}=\frac{v_{p h} e^{2} C(1-C)}{k_{\mathrm{B}} T R} \exp (-2 \alpha R) \exp \left(-W / k_{\mathrm{B}} T\right)
$$

where $v_{\mathrm{ph}}$ is the phonon frequency, $C$ is the fraction of reduced transition metal ion, $\left(\mathrm{Fe}^{2+} / \mathrm{Fe}_{\text {tot }}\right), R$ is the average spacing between transition metal ions, $\alpha$ is the tunnelling factor (ratio of the wave function decay), $e$ is the electronic charge, $k_{\mathrm{B}}$ is the Boltzmann constant, $T$ is absolute temperature and $W$ is the activation energy for the hopping conduction. The activation energy for the jump of polaron between nearest neighbours is defined by the relation $W=W_{\mathrm{h}}+W_{\mathrm{d}} / 2$ where a $W_{\mathrm{h}}$ is the polaron hopping energy and $W_{\mathrm{d}}$ is the energy difference between two neighbouring ions. The value of the activation energy for iron phosphate glasses lies in the range from 40 $\mathrm{kJ} \mathrm{mol}^{-1}$ to $70 \mathrm{~kJ} \mathrm{~mol}^{-1}$. ${ }^{-27}$

At lower temperatures, the temperature dependence of the DC conductivity deviates from the Arrhenius behaviour, the apparent activation energy becoming temperature dependent. ${ }^{28}$ The conduction mechanism in the low-temperature region is usually explained in terms of the variable range hopping (VRH) model in which polaron hopping occurs preferentially beyond nearest neighbouring sites.

\section{Complex Impedance Plot}

Complex impedance plots of binary iron phosphate glasses at each temperature exhibit single semicircle as shown in Figure 5. An important characteristic of these semicircles is that their centers are below the real axis

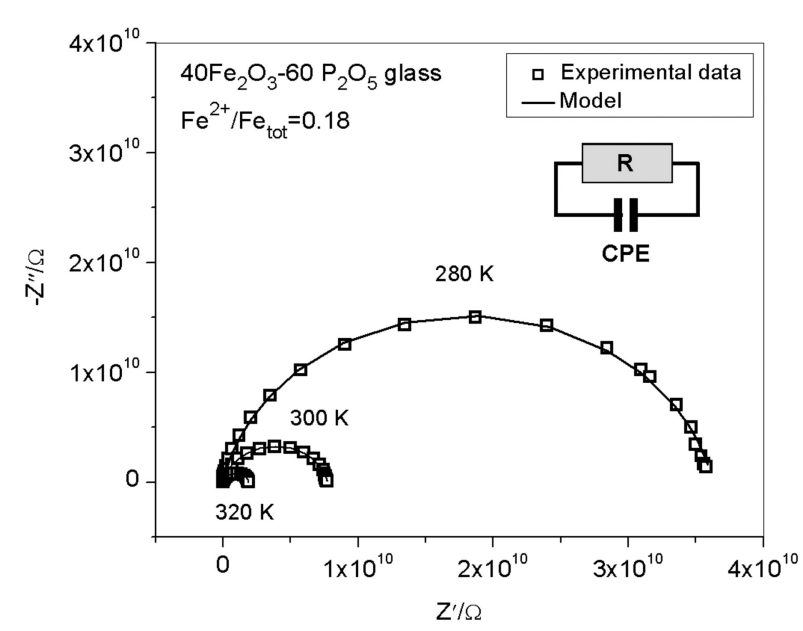

Figure 5. Complex impedance plots at 280, 300 and $320 \mathrm{~K}$ for $40 \mathrm{Fe}_{2} \mathrm{O}_{3}-60 \mathrm{P}_{2} \mathrm{O}_{5}$ (mol \%) glass and the corresponding equivalent circuit used for fitting of the data. Circles denote experimental values, solid line corresponds to the best fit.

indicating the presence of a distribution in relaxation times within the glass. In equivalent circuit modelling, such impedance response is well described by the resistor and constant-phase element (CPE) rather than the ordinary capacitor (compare Figure 1 and Figure 5). ${ }^{15,26}$ From the values of resistance, $R$, calculated by the complex non-linear least square procedure and electrode dimensions ( $A$ is the electrode area and $d$ is the sample thickness) DC conductivity, $\sigma_{\mathrm{DC}}$, can be calculated according to relation $\sigma_{\mathrm{DC}}=d /(A R)$ giving an identical value to the one obtained from the low-frequency part of the conductivity spectra.

It is important to note that the single impedance arc is typical of electronic conduction. ${ }^{26}$ As shown later, ionic conductivity exhibits additional features in the complex plane plot.

\section{ADDITION OF OXIDES TO IRON PHOSPHATE GLASSES}

Addition of other oxides (transition metal oxides, alkali and earth alkali oxides) influences the structure and various physical properties of iron phosphate glass. However, the universal dynamic response and time temperature superposition are usually not affected. Therefore, the investigations of the more complex iron phosphate glasses are presented in terms of the determination of factors that influence electrical conductivity in these glasses.

Selected series of iron phosphate glasses containing different oxides are summarized in Table 1. Within these glass systems it is of interest to study the influence of the following factors: i) addition of second transition metal oxide $\left(\mathrm{MoO}_{3}, \mathrm{Cr}_{2} \mathrm{O}_{3}\right)$, ii) addition of alkali oxide $\left(\mathrm{Na}_{2} \mathrm{O}\right)$ and iii) crystallization. 
Table 1. Selected iron phosphate glass systems

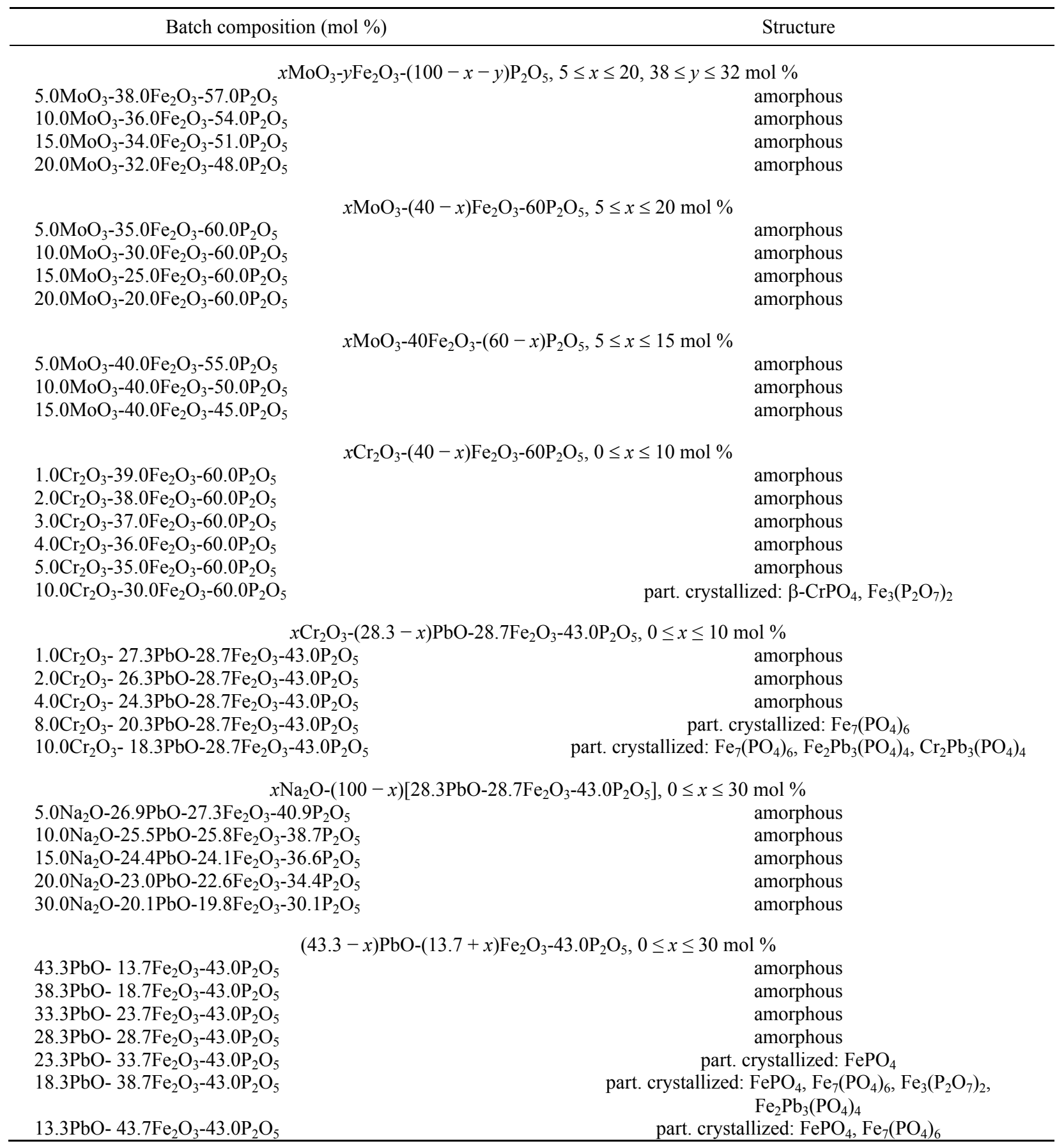

For various oxide glasses it has been reported that the addition of the second transition metal oxide causes specific conductivity anomaly called "mixed transition metal oxide" effect. ${ }^{29,30}$ However, the study ${ }^{31}$ of three glass series containing molybdenum oxide; $x \mathrm{MoO}_{3}$ $y \mathrm{Fe}_{2} \mathrm{O}_{3}-(100-x-y) \mathrm{P}_{2} \mathrm{O}_{5}, 5 \leq x \leq 20,38 \leq y \leq 32$, $x \mathrm{MoO}_{3}-(40-x) \mathrm{Fe}_{2} \mathrm{O}_{3}-60 \mathrm{P}_{2} \mathrm{O}_{5}, 5 \leq x \leq 20$ and $x \mathrm{MoO}_{3}-$ $40 \mathrm{Fe}_{2} \mathrm{O}_{3}-(60-x) \mathrm{P}_{2} \mathrm{O}_{5}, 5 \leq x \leq 15$ (mol \%) showed that the electrical conductivity, $\sigma_{\mathrm{DC}}$, in these glasses strictly follows changes in the $\mathrm{Fe}^{2+} / \mathrm{Fe}_{\text {tot }}$ ratio, Figure 6. This clearly indicates that the conduction process is completely controlled by the polaron hopping between iron ions. One of the possible explanations for this is the existence of molybdenum ions in predominantly single valence state leaving contribution of the charge transfer between molybdenum sites to the total conductivity negligible. Similar results were obtained for the $x \mathrm{Cr}_{2} \mathrm{O}_{3}$ $(40-x) \mathrm{Fe}_{2} \mathrm{O}_{3}-60 \mathrm{P}_{2} \mathrm{O}_{5} 0 \leq x \leq 10(\mathrm{~mol} \%)$ and $x \mathrm{Cr}_{2} \mathrm{O}_{3}-$ $(28.3-x) \mathrm{PbO}-28.7 \mathrm{Fe}_{2} \mathrm{O}_{3}-43.0 \mathrm{P}_{2} \mathrm{O}_{5}, 0 \leq x \leq 10,(\mathrm{~mol} \%)$ glasses. $^{26,27}$ The conduction in these glasses is inde- 

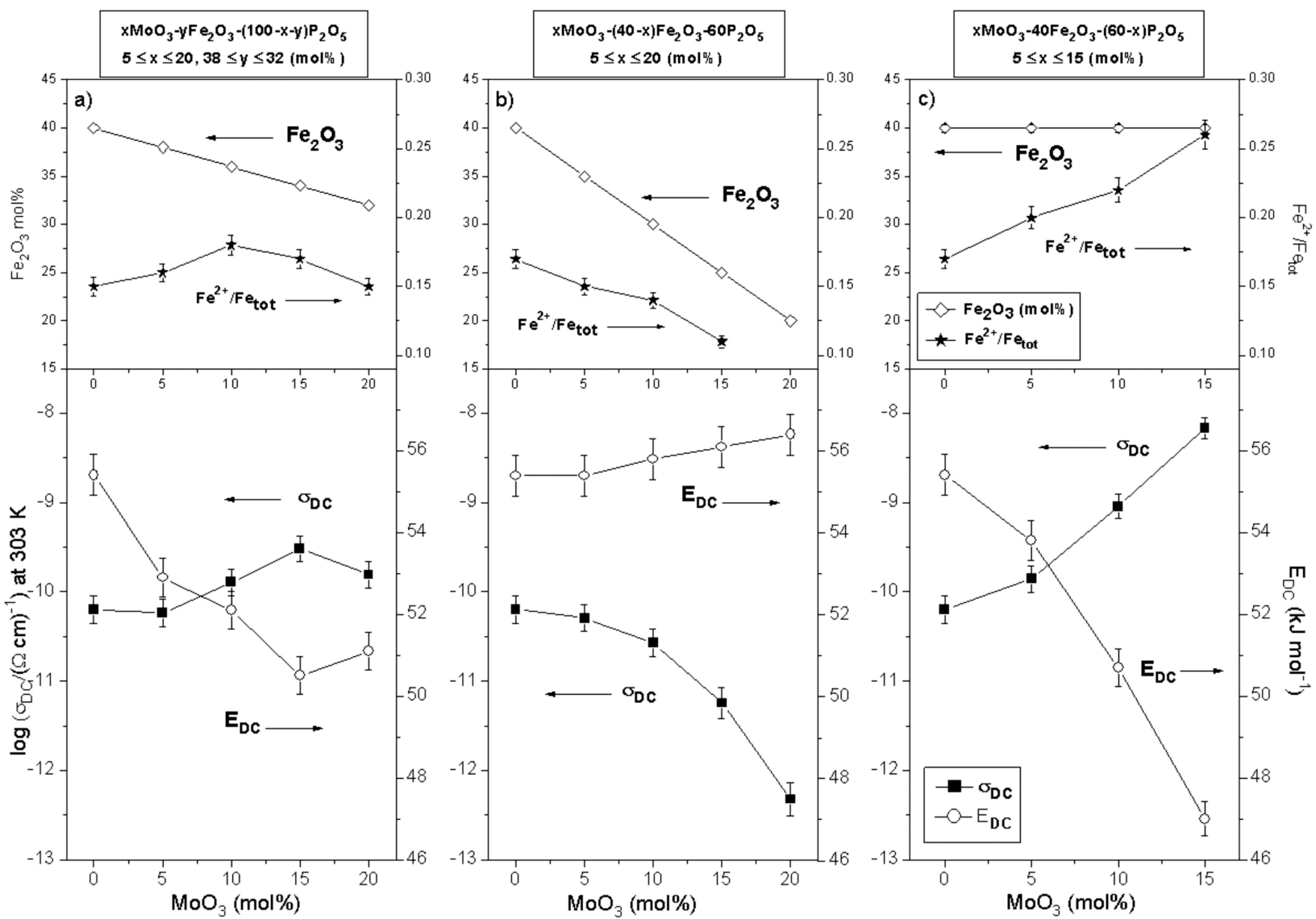

Figure 6. The dependence of the DC conductivity, $\sigma_{\mathrm{DC}}$, at $303 \mathrm{~K}$, activation energy for DC conductivity, $\mathrm{E}_{\mathrm{DC}}$, and $\mathrm{Fe}^{2+} / \mathrm{Fe}_{\mathrm{tot}}$ ratio upon the $\mathrm{MoO}_{3}$ content in $x \mathrm{MoO}_{3}-y \mathrm{Fe}_{2} \mathrm{O}_{3}-(100-x-y) \mathrm{P}_{2} \mathrm{O}_{5}, 5 \leq x \leq 20,38 \leq y \leq 32, x \mathrm{MoO}_{3}-(40-x) \mathrm{Fe}_{2} \mathrm{O}_{3}-60 \mathrm{P}_{2} \mathrm{O}_{5}, 5 \leq x \leq 20$ and $x \mathrm{MoO}_{3}-40 \mathrm{Fe}_{2} \mathrm{O}_{3}-(60-x) \mathrm{P}_{2} \mathrm{O}_{5}, 5 \leq x \leq 15$ (mol \%) glasses. $\mathrm{Fe}^{2+} / \mathrm{Fe}_{\text {tot }}$ ratio was calculated from Mössbauer spectra. Lines are drawn as guides for the eye.

pendent on $\mathrm{Cr}_{2} \mathrm{O}_{3}$ and entirely controlled by the polaron hopping between iron ions.

Generally, the electrical conductivity of alkali containing iron phosphate glasses is mixed ionic-polaronic. The ionic conduction should be proportional to the concentration and mobility of the alkali ions, whereas the electronic conduction follows the polaron hopping theory. A gradual transition from predominantly electronic to predominantly ionic conduction with increasing alkali content is observed in the glass system $x \mathrm{Na}_{2} \mathrm{O}-(100-$ $x)\left[28.3 \mathrm{PbO}-28.7 \mathrm{Fe}_{2} \mathrm{O}_{3}-43.0 \mathrm{P}_{2} \mathrm{O}_{5}\right],{ }^{32} 0 \leq x \leq 30$ (mol \%), Figure 7. Glasses containing $\leq 15 \mathrm{~mol} \% \mathrm{Na}_{2} \mathrm{O}$ show almost constant value of $\sigma_{\mathrm{DC}}$ which is related to the constant $\mathrm{Fe}^{2+} / \mathrm{Fe}_{\text {tot }}$ ratio. In these glasses the sodium ions have such low mobility, probably due to trapping of $\mathrm{Na}^{+}$ ions in the phosphate network, that they make no detectable contribution to the total conductivity. With increasing $\mathrm{Na}_{2} \mathrm{O}$ content, up to $30 \mathrm{~mol} \%$, the total conductivity increases which is directly related to an increase in the mobility of the sodium ions. The change in the nature of the electrical conduction is also visible from the shape of the impedance complex plot, inset in
Figure 7. While the glasses on the polaronic side of the plot exhibit single impedance semicircle typical for electronic transport, the glasses containing 20 and 30 mol $\% \mathrm{Na}_{2} \mathrm{O}$ show characteristic spur at low frequencies. This feature is related to the blocking of $\mathrm{Na}^{+}$ions at the $\mathrm{Au}$ electrodes indicating significant ionic conduction in these samples.

The structural studies on the series of (43.3 $x) \mathrm{PbO}-(13.7+x) \mathrm{Fe}_{2} \mathrm{O}_{3}-43.0 \mathrm{P}_{2} \mathrm{O}_{5}(0 \leq x \leq 30)$ glasses $^{33}$ showed partially crystallization. With increasing molar $\mathrm{O} / \mathrm{P}$ ratio and fraction of $\mathrm{Fe}^{2+}$ ions, the length of phosphate units decreases which causes a higher crystallization tendency of the melt, see Table 1. The electrical conductivity within this series is strongly affected by the crystallization, Figure 8. For fully amorphous glasses with $\leq 30 \mathrm{~mol} \% \mathrm{Fe}_{2} \mathrm{O}_{3}$, electrical conductivity increases with the increase of $\mathrm{Fe}^{2+} / \mathrm{Fe}_{\text {tot }}$ indicating polaronic transport. On the other hand, the electrical conductivity of the partially crystallized samples decreases despite the increase in $\mathrm{Fe}^{2+} / \mathrm{Fe}_{\text {tot }}$ ratio which can be attributed to a massive crystallization of several crystalline phases: $\mathrm{Fe}_{7}\left(\mathrm{PO}_{4}\right)_{6}, \mathrm{Fe}_{3}\left(\mathrm{P}_{2} \mathrm{O}_{7}\right)_{2}, \mathrm{Fe}_{2} \mathrm{~Pb}_{3}\left(\mathrm{PO}_{4}\right)_{4}$ and $\mathrm{FePO}_{4}$, see 


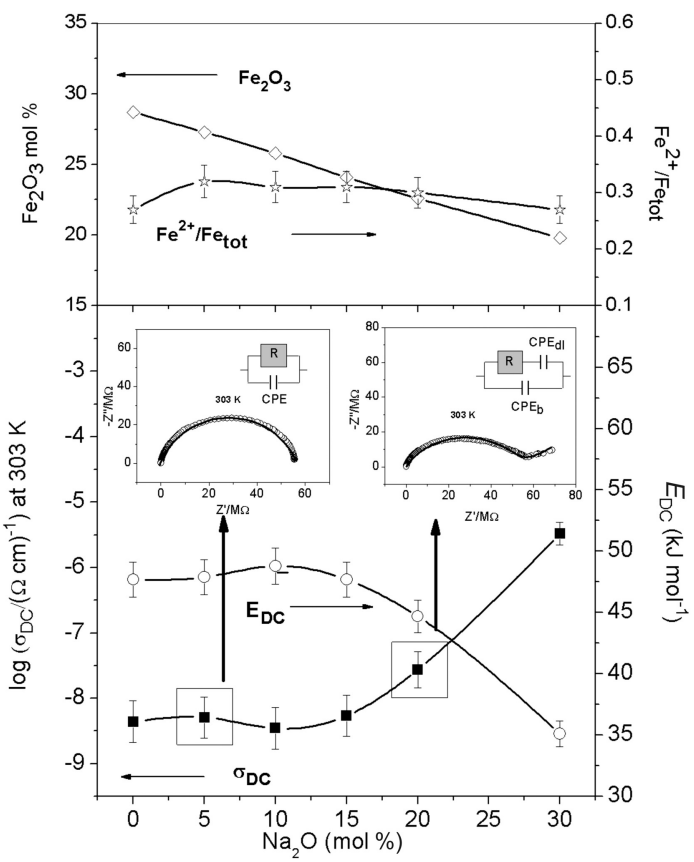

Figure 7. The dependence of the DC conductivity, $\sigma_{\mathrm{DC}}$, at 303 $\mathrm{K}$, activation energy for $\mathrm{DC}$ conductivity, $\mathrm{E}_{\mathrm{DC}}$, and $\mathrm{Fe}^{2+} / \mathrm{Fe}_{\text {tot }}$ ratio upon the $\mathrm{Na}_{2} \mathrm{O}$ content in $x \mathrm{Na}_{2} \mathrm{O}-(100-x)$ [28.3PbO$\left.28.7 \mathrm{Fe}_{2} \mathrm{O}_{3}-43.0 \mathrm{P}_{2} \mathrm{O}_{5}\right], 0 \leq x \leq 30$ ( $\mathrm{mol} \%$ ), glasses. Lines are drawn as guides for the eye. Inset: Complex impedance plots at $303 \mathrm{~K}$ for $5 \mathrm{Na}_{2} \mathrm{O}-26.9 \mathrm{PbO}-27.3 \mathrm{Fe}_{2} \mathrm{O}_{3}-40.9 \mathrm{P}_{2} \mathrm{O}_{5}(\mathrm{~mol} \%)$ and $20 \mathrm{Na}_{2} \mathrm{O}-23.0 \mathrm{PbO}-22.6 \mathrm{Fe}_{2} \mathrm{O}_{3}-34.4 \mathrm{P}_{2} \mathrm{O}_{5}(\mathrm{~mol} \%)$ glasses and their corresponding equivalent circuits. Circles denote experimental values, solid line corresponds to the best fit.

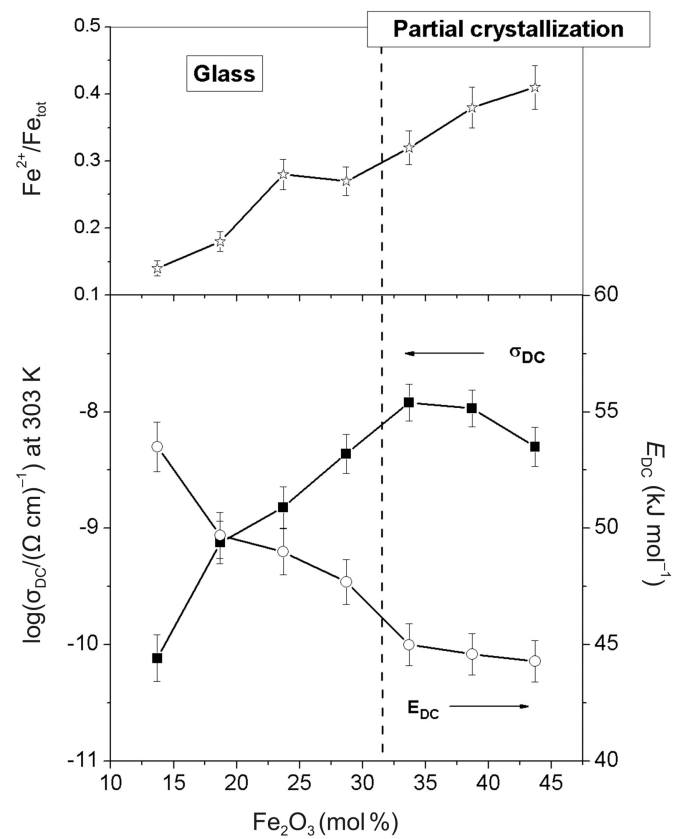

Figure 8. The dependence of the DC conductivity, $\sigma_{\mathrm{DC}}$, at 303 $\mathrm{K}$, activation energy for $\mathrm{DC}$ conductivity, $\mathrm{E}_{\mathrm{DC}}$, and $\mathrm{Fe}^{2+} / \mathrm{Fe}_{\text {tot }}$ ratio upon the $\mathrm{Fe}_{2} \mathrm{O}_{3}$ content in $(43.3-x) \mathrm{PbO}-(13.7+x)$ $\mathrm{Fe}_{2} \mathrm{O}_{3}-43.0 \mathrm{P}_{2} \mathrm{O}_{5}, 0 \leq x \leq 30$ (mol \%) glasses. Lines are drawn as guides for the eye.
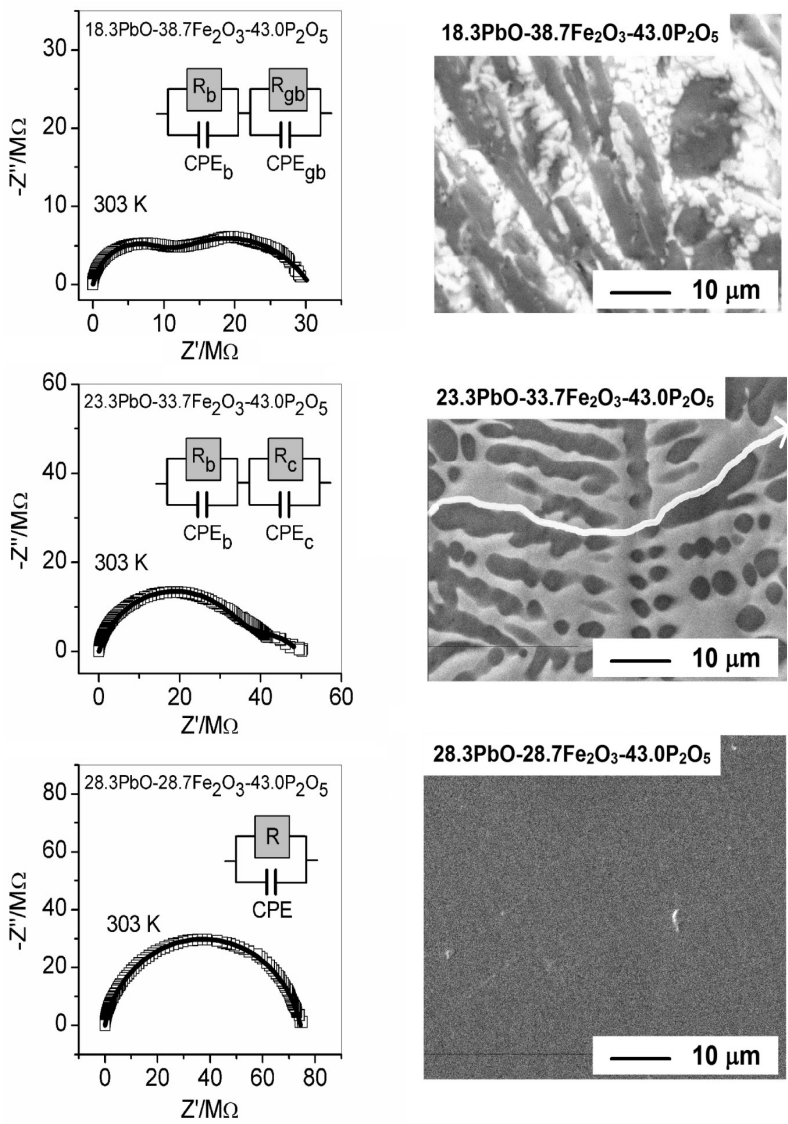

28.3PbO-28.7 $\mathrm{Fe}_{2} \mathrm{O}_{3}-43.0 \mathrm{P}_{2} \mathrm{O}_{5}$

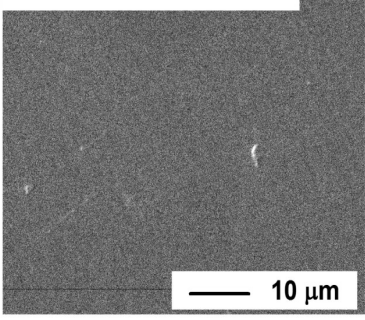

Figure 9. Complex impedance plots, corresponding equivalent circuits and SEM micrographs for 28.3PbO-28.7 $\mathrm{Fe}_{2} \mathrm{O}_{3}$ 43.0 $\mathrm{P}_{2} \mathrm{O}_{5}, \quad 23.3 \mathrm{PbO}-33.7 \mathrm{Fe}_{2} \mathrm{O}_{3}-43.0 \mathrm{P}_{2} \mathrm{O}_{5}$ and 18.3PbO$38.7 \mathrm{Fe}_{2} \mathrm{O}_{3}-43.0 \mathrm{P}_{2} \mathrm{O}_{5}$ glasses. Circles denote experimental values, solid line corresponds to the best fit. The arrow in the $\mathrm{SEM}$ micrograph of $23.3 \mathrm{PbO}-33.7 \mathrm{Fe}_{2} \mathrm{O}_{3}-43.0 \mathrm{P}_{2} \mathrm{O}_{5}$ glass represents the "easy conduction pathway".

Table 1 and SEM micrograph in Figure 9. However, it is interesting to note that the electrical conductivity of partially crystallized sample of composition $23.3 \mathrm{PbO}-$ $33.7 \mathrm{Fe}_{2} \mathrm{O}_{3}-43.0 \mathrm{P}_{2} \mathrm{O}_{5}$ is still considerably high. This effect can be attributed to the fast conduction at the interfaces between crystallites and glassy phase. Since the crystalline grains in this sample are not adhered to each other, SEM image in Figure 9, the interface phase between them and the glassy matrix is extensive and continuous. We assume that these interfacial regions with a highly disruptive structure can form the easy conductive pathways responsible for the high conductivity. This is in a good agreement with the recently reported investigation of lithium iron phosphate glasses, ${ }^{34}$ where the interface regions between nanocrystallites and amorphous phase rich in $\mathrm{Fe}^{2+}$ and $\mathrm{Fe}^{3+}$ pairs were crucial for the increase in conductivity. Similar results were obtained for $x \mathrm{Cr}_{2} \mathrm{O}_{3}-(40-x) \mathrm{Fe}_{2} \mathrm{O}_{3}$ $60 \mathrm{P}_{2} \mathrm{O}_{5}, 0 \leq x \leq 10(\mathrm{~mol} \mathrm{\%})$ and $x \mathrm{Cr}_{2} \mathrm{O}_{3}-(28.3-x) \mathrm{PbO}-$ 


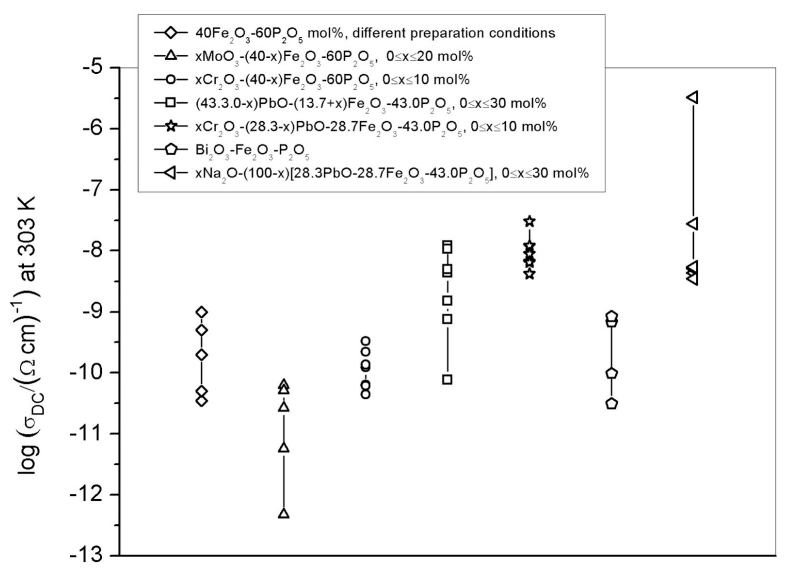

Figure 10. The DC conductivity at $303 \mathrm{~K}$ for different iron phosphate glass systems.

$28.7 \mathrm{Fe}_{2} \mathrm{O}_{3}-43.0 \mathrm{P}_{2} \mathrm{O}_{5}, 0 \leq x \leq 10(\mathrm{~mol} \%)$ glasses where partial crystallization was observed. ${ }^{26,27}$ It is important to note that the structural changes in this glass system are also reflected in the shape of the impedance response in complex plane, Figure 9. All glassy samples show single semicircle indicating single polaronic conduction mechanism. On the contrary, spectra of crystallized samples consist of two poorly resolved semicircles indicating two contributions. The high frequency one corresponds to the crystalline grains, while, low frequency one corresponds to the interface between them. These contributions can be separated by equivalent circuit modelling (shown in the graphs) and with a help of structural analysis (fractions and nature of crystalline phase(s), size, shape and distribution of crystalline grains) a detailed characterization of such polycrystalline material can be obtained. ${ }^{35}$

\section{CONCLUSIONS}

Iron phosphate glasses are electronically conducting glasses with polaronic conduction mechanism where conduction takes place by electrons hopping from $\mathrm{Fe}^{2+}$ to $\mathrm{Fe}^{3+}$. The critical factor for polaronic conductivity is $\mathrm{Fe}^{2+} / \mathrm{Fe}_{\text {tot }}$ ratio. However, with addition of significant amount of alkali oxide $\left(\mathrm{Na}_{2} \mathrm{O}\right)$ conductivity mechanism in these glasses changes to ionic. In partially crystallized samples electrical conductivity strongly depends on the microstructure. The investigation of several multicomponent glass systems based on iron phosphates shows that by altering composition and preparation conditions, the electrical conductivity of iron phosphate based glasses may vary over many orders of magnitude, Figure 10.

Acknowledgements. The authors are pleased to acknowledge Prof. Delbert E. Day (Missouri University of Science and Technology, Rolla, USA) and members of his group for a long-time collaboration in the field of iron phosphate glasses. This work was supported by Croatian Ministry of Science, Education and Sports, projects: «Influence of structure on electrical properties of (bioactive) glasses and ceramics» (0980982929-2916).

\section{REFERENCES}

1. R. A. Serway, J. W. Jewett, Principles of Physics: A Calculus-based Text, $4^{\text {th }}$ Edition, Thomson, Brooks Cole Publishing, 2006, p 689.

2. M. Shapaan, E. R. Shabaan, and A. G. Mostafa, Physica B 404 (2009) 2058-2064.

3. Y. M. Moustafa, J. Mater. Sci-Mater. El. 6 (1995) 135-139.

4. D. E. Day, Z. Wu, C. S. Ray, and P. Hrma, J. Non-Cryst. Solids 241 (1998) 1-12.

5. M. G. Mesko, D. E. Day, and B. C. Bunker, Science and Technology for Disposal of Radioactive Tank Wastes, Plenium Press, New York, 1997, p. 379.

6. X. Yu, D. E. Day, G. J. Long, and R. K. Brow, J. Non-Cryst. Solids 215 (1997) 21-31.

7. G. N. Greaves, S. J. Gurman, L. F. Gladden, C. A. Spence, P. Cox, B. C. Sales, L. A. Boatner, and R. N. Jenkins, Philos. Mag. $B 58$ (1988) 271-283.

8. M. Sayer and A. Mansingh, Phys. Rev. B 6 (1972) 4629-4643.

9. K. W. Hansen, J. Electrochem. Soc. 112 (10) (1965) 994-996.

10. L. Murawski, C. H. Chung, and J. D. Mackenzie, J. Non-Cryst. Solids 32 (1979) 91-104.

11. N. F. Mott, J. Non-Cryst. Solids 1 (1968) 1-17.

12. A. I. G. Austin and N. F. Mott, Adv. Phys. 18 (1969) 41-102.

13. A. Moguš-Milanković, D. E. Day, and B. Šantić, Phys. Chem. Glasses 40 (1999) 69-74.

14. A. Moguš-Milanković, A. Šantić, A. Gajović, and D. E. Day, J. Non-Cryst. Solids 296 (2001) 57-64.

15. J. R. Macdonald (Ed.), Impedance Spectroscopy, Wiley, New York, 1987.

16. T. S. Irvine, D. C. Sinclair, and A. R. West, Adv. Mater. 2 (1990) 132-138.

17. R. K. Brow, J. Non-Cryst. Solids, 263-264 (2000) 1-28.

18. A. Moguš-Milanković, A. Gajović, A. Šantić, and D. E. Day, J. Non-Cryst. Solids 289 (2001) 204-213.

19. X. Fang, C. S. Ray, A. Moguš-Milanković, and D. E. Day, J. Non-Cryst. Solids 283 (2001) 162-172.

20. D. L. Sidebottom, B. Roling, and K. Funke, Phys. Rev. B 63 (1972) 24301 1-7.

21. J. C. Dyre, P. Maass, B. Roling, and D. L. Sidebottom, Rep. Prog. Phys. 72 (2009) 046501.

22. S. Murugavel and M. Upadhyay, J. Indian. Inst. Sci. 91 (2) (2011) 303-317.

23. A. K. Jonscher, Nature 267 (1977) 673-679.

24. S. Summerfield, Phil. Mag. B 52 (1985) 9.

25. A. Moguš-Milanković, A. Šantić, V. Ličina, and D. E. Day, J. Non-Cryst. Solids 351 (2005) 3235-3245.

26. A. Šantić, C. W. Kim, D. E. Day, and A. Moguš-Milanković, J. Non-Cryst. Solids 356 (2010) 2699-2703.

27. A. Šantić, Ž. Skoko, A. Gajović, S. T. Reis, D. E. Day, and A. Moguš-Milanković, J. Non-Cryst. Solids 357 (2011) 3578-3584.

28. B. Šantić, A. Moguš-Milanković, and D. E. Day, J. Non-Cryst. Solids 296 (2001) 65-73.

29. B. Dutta, N. A. Fahmy, and I. L. Pegg, J. Non-Cryst. Solids 351 (2005) 1958-1966.

30. B. Dutta, N. A. Fahmy, and I. L. Pegg, J. Non-Cryst. Solids 351 (2005) 2552-2561.

31. A. Moguš-Milanković, A. Šantić, M. Karabulut, and D. E. Day, J. Non-Cryst. Solids 330 (2003) 128-141. 
32. A. Moguš-Milanković, A. Šantić, S. T. Reis, K. Furić, and D. E. Day, J. Non-Cryst. Solids 342 (2004) 97-109.

33. A. Moguš-Milanković, A. Šantić, S. T. Reis, K. Furić, and D. E. Day, J. Non-Cryst. Solids 351 (2005) 3246-3258.
34. J. E. Garbarczyk, M. Wasiucionek, P. Jozwiak, J. L. Nowinski, and C. M. Julien, Solid State Ionics 180 (2009) 531-536.

35. L. Pavić, Dissertation in progress, Faculty of Science, University of Zagreb. 